\title{
A Normative Observational Study of the Relationship of the Philtral Ridges to the Columellar Base in South- Indian Population and its Significance on Cleft Lip Repair
}

\author{
Deyonna Deepthi Fernandes ${ }^{1}$ Syed Altaf Hussain ${ }^{1, \odot}$ \\ ${ }^{1}$ The Department of Plastic Surgery, The Cleft and Craniofacial \\ Center, Sri Ramachandra University Hospital, Chennai, Tamil Nadu, \\ India \\ Address for correspondence Syed Altaf Hussain, MS FRCS DNB, The \\ Cleft and Craniofacial Center, Sri Ramachandra University Hospital, \\ Chennai, Tamil Nadu, 600 116, India \\ (e-mail: sa_hussain@hotmail.com).
}

Indian J Plast Surg 2021;54:334-337.

\begin{abstract}
Introduction The philtral ridges form a prominent visual landmark in the upper lip. An aesthetically pleasing cleft lip repair should restore this preferably without any scars cutting across it. Although there are several scientific publications on morphology of this structure and its variations, very few studies on the Indian population have been published.

Aim To study the morphology of the philtral ridges and their relationship to the columellar base in normal Indian children and its significance in cleft lip repair.

Methods 115 normal healthy children from southern India aged between one and 12 years were studied based on direct observation of the relationship of the superior end of the philtral ridge to the columellar base and nasal sill. In type $A$, the philtral ridge terminates at the nasal sill just lateral to the columellar base, and in type $B$, it either reaches or fades before reaching the columellar base. All observations were performed by the first author by examining standardized two-dimensional (2D) photographs of the upper lip-nose complex.

Keywords Results In this study, $74 \%$ of the subjects had the philtral column extending lateral

- Philtrum to the columellar base.

- Philtral ridge

Conclusion These finding assume a significance since, in a substantial proportion of

- Cleft Lip

- Scar

- Morphology the studied population, techniques of cleft lip repair such as the rotation advancement method, place a scar that crosses the upper third of the philtral ridge which may be undesirable.
\end{abstract}

An understanding of the morphological characteristics of the normal philtral ridges in our population is essential for the right choice of incision in cleft lip reconstruction.

published online

September 16, 2021
DOI https://doi.org/

$10.1055 / \mathrm{s}-0041-1734571$ ISSN 0970-0358

\section{Introduction}

There is a complex and delicate relationship between the shape and proportions of philtral ridges, base of the columella (c) 2021. Association of Plastic Surgeons of India.

This is an open access article published by Thieme under the terms of the Creative Commons Attribution-NonDerivative-NonCommercial-License, permitting copying and reproduction so long as the original work is given appropriate credit. Contents may not be used for commercial purposes, or adapted, remixed, transformed or built upon. (https://creativecommons.org/licenses/by-nc-nd/4.0/).

Thieme Medical and Scientific Publishers Pvt. Ltd. A-12, 2nd Floor, Sector 2, Noida-201301 UP, India 
nasi, and the rest of the lip, which plays an important role in its normal appearance. It is well-accepted that these structures exhibit differences among individuals and may also have racial variations. ${ }^{1}$ Understanding the normal morphology and its variations is essential to achieve symmetry and a near-normal appearance during cleft lip repair. This is particularly important, since the surgeon needs to position the incisions to preserve the philtral ridges or simulate them. In the unilateral cleft, this must correspond to its opposite side, while in the bilateral, it should form or simulate the structure in accordance with the shape of the philtral columns and its relationship to the nostril prevailing in the local population.

The rotation advancement technique or its variants, undoubtedly one of the most popular operations for cleft lip repair, assumes that the philtral ridges end at the columellar base. Hence, the incisions are designed to simulate these to achieve a normal looking lip. However, it was the observation of Jyotsna Murthy that in a significant number of our patients, this assumption does not hold good and the philtral ridge ended lateral to the columellar base into the nasal sill. (Personal communication) In these patients, the rotation incision including the Mohler's modification cuts across the upper third of the philtral column, placing the incision across this landmark structure.

Although normative data from anthropological studies of the lip and philtral ridges have been published from different parts of the world, none was found to emphasize the variations in its relationship with the columellar bases. Further, there are no studies regarding these variations in the south Indian population.

\section{Aim and Objectives}

To describe the morphology of philtral ridges of the lip and their relationship to the columellar bases in a sample of the south Indian population. The objective of this observational study is to achieve this by determining whether the upper end of the philtral ridge terminates at the columellar base or further laterally in the nasal sill.

\section{Methods}

A total of 115 healthy children with no known congenital anomalies from the southern Indian states of Tamil Nadu and Karnataka were evaluated. There were 88 boys and 27 girls. The ages ranged between one and twelve years.

Inclusion criteria: Children reporting for routine immunization to the hospital and school children without any visible congenital or other anomalies were studied. A printed consent was obtained from one or both parents.

Exclusion criteria: Children with congenital anomalies and those who were crying or exhibiting behavior where the lips were not in repose and whose parents/parent did not provide consent for the study.

Following direct observation and recording of findings by the principal investigator, standard two-dimensional (2D) frontal view photographs of the upper lip were taken using flash photography for the record and further evaluation.
All children were photographed with the lips in repose. The objective lens was positioned at a prefixed distance of one meter from the subject for standardization. The images were then cropped to fill the frame as shown in - Fig. 1.

The study subjects were assigned to one of the two groups by the principal investigator (R1), according to the relationship of the upper pole of the philtral ridges to the columellar base.

Type A: The upper pole of the philtral ridge terminates at the medial nasal sill just lateral to the columellar base (-Fig. 1 A) Type B: The philtral ridge terminates at the columellar base or fades before reaching the columellar base (-Fig. 1 B).

All observations were further evaluated again by two independent observers (R2 and R3), using the standardized $2 \mathrm{D}$ photographs, and the results were ratified. In cases where there was a dispute between the findings of the observers, the type was assigned according to the majority finding. The whole exercise of evaluating the photographs by $\mathrm{R} 2$ and R3 was repeated after an interval of 48 hours to establish intrarater reliability. Descriptive statistical analysis using software SPSS 21 was used to assess reliability.

\section{Results}

Of the 115 evaluated, 100 children whose images satisfied all the required parameters were included in the study. Our findings were type A (philtral ridges extend lateral to the columellar base to end in the medial nasal sill) 74\%; type B (The philtral ridges terminate at the columellar base or fades before reaching the columellar base) $26 \%$ (-Table 1). There is a statistical significance difference between type A and type B at $95 \%(p<0.05)$ (-Table 2). All the observers (R1, R2, and R3) unanimously agreed in their evaluations in these cases (interrater reliability) and were consistent on intrarater reliability tests ( - Table $\mathbf{3}$ ).

\section{Discussion}

With its prominent central position on the lip and complex anatomy, it is imperative that better understanding of the morphology of the philtral ridges will lead to better aesthetic outcomes in cleft lip repair. The present study concentrates on this complex relationship between the philtral ridges, the columella and the nasal sill, because of its significance in the
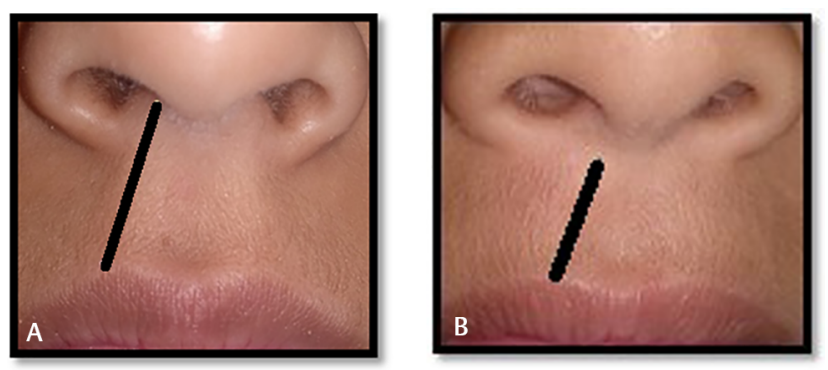

Fig. 1 (A) The Philtral ridge terminates at the medial nasal sill lateral to the columellar base. (B) The Philtral ridge terminates at the columellar base or fades before reaching it. 
Table 1 Observer's evaluation of the philtral ridge to the columellar base

\begin{tabular}{|l|l|l|l|l|l|l|}
\hline $\begin{array}{l}\text { Relationship of philtral ridge to columella } \\
\text { base }\end{array}$ & $\mathbf{R} 1$ & $\begin{array}{l}\mathbf{>} 48 \\
\text { hours }\end{array}$ & $\mathbf{R 2}$ & $\begin{array}{l}\mathbf{>} 48 \\
\text { hours }\end{array}$ & $\mathbf{R 3}$ & $>\mathbf{4 8}$ hours \\
\hline $\begin{array}{l}\text { Type A: philtral ridges extend lateral to the colu- } \\
\text { mellar base to end in the medial nasal sill }\end{array}$ & 74 & 72 & 71 & 75 & 74 & 75 \\
\hline $\begin{array}{l}\text { Type B: philtral ridges terminate at the columel- } \\
\text { lar base or fades before reaching the columellar } \\
\text { base }\end{array}$ & 26 & 28 & 29 & 25 & 26 & 25 \\
\hline
\end{tabular}

Table 2 Group statistics

\begin{tabular}{|c|c|c|c|c|c|c|c|}
\hline & Groups & $n$ & Mean & SD & Standard error mean & $\mathrm{t}$ value & $p$-value \\
\hline \multirow[t]{2}{*}{ R1 } & Type A & 72 & 1.03 & 0.165 & 0.020 & -24.407 & 0.000 \\
\hline & Type B & 28 & 1.96 & 0.189 & 0.036 & & \\
\hline \multirow[t]{2}{*}{$\mathrm{R} 2$} & Type A & 72 & 1.04 & 0.201 & 0.024 & -20.929 & 0.000 \\
\hline & Type B & 28 & 1.96 & 0.189 & 0.036 & & \\
\hline \multirow[t]{2}{*}{ R3 } & Type A & 72 & 1.03 & 0.165 & 0.020 & -20.535 & 0.000 \\
\hline & Type B & 28 & 1.93 & 0.262 & 0.050 & & \\
\hline \multirow[t]{2}{*}{ R1_after_48_hrs } & Type A & 72 & 1.03 & 0.165 & 0.020 & -24.407 & 0.000 \\
\hline & Type B & 28 & 1.96 & 0.189 & 0.036 & & \\
\hline \multirow[t]{2}{*}{ R2_after_48_hrs } & Type A & 72 & 1.03 & 0.165 & 0.020 & -30.990 & 0.000 \\
\hline & Type B & 28 & 2.00 & 0.000 & 0.000 & & \\
\hline \multirow[t]{2}{*}{ R3_after_48_hrs } & Type A & 72 & 1.03 & 0.165 & 0.020 & -24.407 & 0.000 \\
\hline & Type B & 28 & 1.96 & 0.189 & 0.036 & & \\
\hline
\end{tabular}

Abbreviation: SD, standard deviation

Table 3 Inter- and intrarater reliability

\begin{tabular}{|l|l|l|l|l|l|l|}
\hline & R1 & $\mathbf{>}$ 48 hours & R2 & $>$ 48 hours & R3 & > 48 hours \\
\hline Type A & 0.481 & 0.481 & 0.518 & 0.481 & 0.481 & 0.481 \\
\hline Type B & 0.296 & 0.296 & 0.552 & - & 0.386 & 0.296 \\
\hline
\end{tabular}

choice of incisions for cleft lip repair, which can place scars that can potentially distort these structures.

In our study, we found that $74 \%$ of the subjects fell under type A, where the philtral ridges extended lateral to the columellar base to terminate at the medial end of the nasal sill. (-Fig. 1). Surprisingly, the phenotypic variation where the philtral ridges terminated at the columellar base or faded before reaching it (type $\mathrm{B}$ ), which coincides with the conventional descriptions of the philtral column, accounted for only $26 \%$ of the subjects studied. ${ }^{2}$ This may be presumed to be a racial variation, since the ancestral south Indian population, although an admixture of several races, is thought to be distinct from the populations from the other parts of the subcontinent. ${ }^{3}$

Several anatomical studies have already described a complex interplay of the muscle fibers of nasalis, orbicularis oris, levator labii superioris, and their subcutaneous insertions, forming the philtral ridges. ${ }^{4,5}$ Namnoum et al demonstrated in their studies that the philtral ridges are formed by thickened dermis and dermal appendages. ${ }^{6}$ They showed that the muscle fibers of the superficial orbicularis oris were especially rich near the vermilion border and become sparse as they come close to the base of columella nasi. An understanding of this complex relationship of components of orbicularis oris muscle and the overlying dermis is useful in planning the incision and the reconstruction of a consistent philtral column in a cleft lip repair. ${ }^{7}$

The landmark study by Mori et al, which classified the variations in the shapes of the philtral complex in 109 Japanese children, recognized the significance of its relationship to the columella of the nose when they classified it into four distinct groups. ${ }^{8}$ The findings of this study corroborate the prevalence of distinct differences in facial morphology in individuals as well as varying trends among ethnic groups and races. ${ }^{9-11}$ This emphasizes the need for separate standards of facial morphology for different ethnic groups.

The ultimate aim of cleft lip repair is to make the child appear normal. Although complete normalcy is not possible at the present time due to our inability to prevent scarring, near normal results are only possible when scars from the lip repair do not cross the natural landmarks such as philtral ridges.

The rotation advancement method originally described by Millard, and its variations, result in the scar arching from cupid's peak cranially across the upper one third of the philtral column. ${ }^{12}$ Mohler recognized this in his study of the philtral ridges of elementary school children, which he classified 

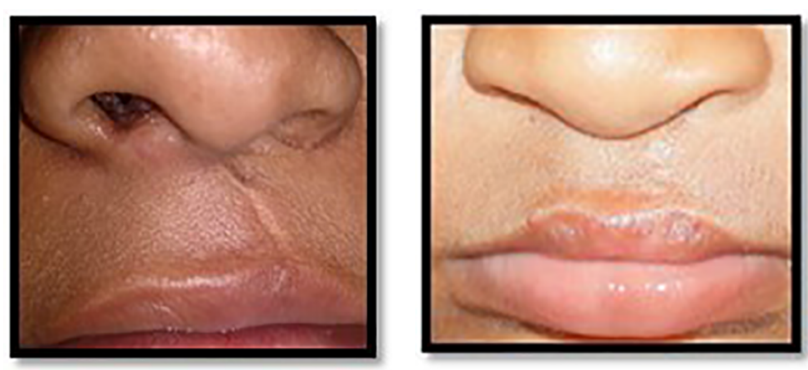

Fig. 2 Comparison of scars following lip repair by rotation advancement and straight-line techniques. (A) Rotation advancement repair with the scar extending to the columellar base. (B) Straight-line repair with the scar extending lateral to the columella into the nasal sill region (please note the overall aesthetics and symmetry).

according to their relationship to the columella. ${ }^{2}$ He found that in most cases, philtral ridges diverged at the columellar base to reach the lateral border of the columella. This was the basis of his modification of the rotation advancement method and for using the columellar base as a silent donor site. Although he also noted that in $7 \%$ of children, the philtral ridge faded out before reaching the columellar base, he did not describe any subject where the philtral ridge diverges well away from the columellar base to end at the nasal sill lateral to it, as in the subjects classified as type A (74\%) in our study.

Hence, it may be argued that the variants of rotation advancement technique of cleft lip repair, including the Mohler's modification, may place incisions that cross its upper one-third, resulting in an unacceptable scar across the philtral ridge in a substantial portion of our population ( - Fig. 2 A). The straight-line repair or its variations where the scar extends to the nasal sill along the line of cleft may be more appropriate in these patients, since the incision preserves the philtral column, which is essential for a near-normal appearance of the repaired lip.

Although we consider our findings to be significant to initiate a discussion on the preference of technique for cleft lip repair in this part of the world, a larger study with a comparison of the populations from various regions of the subcontinent with larger sample sizes may be needed for conclusive evidence.

\section{Conclusion}

The surgeon should take into consideration the racial and ethnic variations in morphology of the philtral ridges in the local population while choosing an appropriate technique for cleft lip repair.

\section{Declaration}

This study has conformed to the Declaration of Helsinki and has been honored.

\section{Financial disclosures \\ None.}

\section{Conflict of Interest}

None declared.

\section{References}

1 Kishi N, Tanaka S, Iida S, Kogo M. Comprehensive evaluation of three-dimensional philtral morphology. J Craniofac Surg 2011;22(5):1606-1611

2 Mohler LR. Unilateral cleft lip repair. Plast Reconstr Surg 1987;80(4):511-517

3 Reich D, Thangaraj K, Patterson N, Price AL, Singh L. Reconstructing Indian population history. Nature 2009;461(7263):489-494

4 Latham RA, Deaton TG. The structural basis of the philtrum and the contour of the vermilion border: a study of the musculature of the upper lip. J Anat 1976;121(Pt 1):151-160

5 Briedis J, Jackson IT. The anatomy of the philtrum: observations made on dissections in the normal lip. Br J Plast Surg 1981;34(2):128-132

6 Namnoum JD, Hisley KC, Graepel S. Hutchins GN, Vander Kolk CA. Three-dimensional reconstruction of the human fetal philtrum. Ann Plast Surg 1997;38(3):202-208

7 Rogers CR, Meara JG, Mulliken JB. The philtrum in cleft lip: review of anatomy and techniques for construction. J Craniofac Surg 2014;25(1):9-13

8 Mori A, Nakajima T, Kaneko T, Sakuma H, Aoki Y. Analysis of 109Japanese children's lip and nose shapes using 3-dimensional digitizer. Br J Plast Surg 2005;58(3):318-329

9 Yamada T, Mori Y, Minami K, Mishima K, Tsukamoto Y. Three-dimensional analysis of facial morphology in normal Japanese children as control data for cleft surgery. Cleft Palate Craniofac J 2002;39(5):517-526

10 Nakamura N, Suzuki A, Takahashi H, Honda Y, Sasaguri M, Ohishi M. A longitudinal study on influence of primary facial deformities on maxillofacial growth in patients with cleft lip and palate. Cleft Palate Craniofac J 2005;42(6):633-640

11 Schwenzer-Zimmerer K, Chaitidis D, Berg-Boerner I, et al. Quantitative 3D soft tissue analysis of symmetry prior to and after unilateral cleft lip repair compared with non-cleft persons (performed in Cambodia. J Craniomaxillofac Surg 2008;36(8):431-438

12 Millard DR Jr, Dr M. Rotation-advancement versus Giraldes' cleft lip technique. Plast Reconstr Surg Transplant Bull 1961;28(5):595-597 